\title{
Evaluation of the Bond Strength of Universal Tray Adhesives on Silicone Impression Materials Using an Acrylic Tray
}

\author{
Sapna C Kambiranda ${ }^{1}$, Brilvin Pinto ${ }^{2}$, Mohamed A Elpatal ${ }^{3}$, George Sam ${ }^{4}$, Adamane S Chaitra ${ }^{5}$, Rautredilla P Rani ${ }^{6}$
}

\begin{abstract}
Aim:To evaluate the bond strength of two commercially available universal tray adhesives on polyvinylsiloxane addition silicone and condensation silicone impression materials to an autopolymerizing polymethyl methacrylate acrylic tray material.

Materials and methods: Sixty flat square specimens were fabricated from autopolymerizing polymethyl methacrylate tray material to which an eye hook was incorporated to serve as the point of attachment to a universal testing machine. A polyvinyl chloride (PVC) pipe of $15 \mathrm{~mm}$ diameter and $25 \mathrm{~mm}$ long was used to house the impression material, and a metal rod was inserted into two centered holes to provide retention that serves as the second point of attachment to the universal testing machine. The specimens were divided into 4 groups of 15 specimens each. The first and second groups of specimens were applied with Coltene and Zhermack universal tray adhesives and tested with addition silicone impression material. The third and fourth groups were coated with the above-mentioned adhesives, respectively, and tested with condensation silicone. Each specimen was then attached to the universal testing machine. The maximum force at which separation failure occurred was divided by the area of adhesion and recorded as the adhesive strength in MPa.

Results: A significant difference was observed between mean MPa values of Zhermack and Colten universal tray adhesives, where the $F$ value of 1314.116 was found to be significant at 0.000 levels indicating that the Zhermack adhesive had higher MPa than Coltene adhesive. Impression material again indicated significant difference $(F=132.514 ; p=0.000)$, where addition silicone had higher MPa value than condensation silicone. Also, the interaction between adhesive and impression material was found to be significant $(F=10.794 ; p=0.002)$.

Conclusion: The adhesive bond strength of Zhermack universal tray adhesive was higher compared to that of Coltene universal tray adhesive irrespective of the elastomeric impression material. It was also found that bond strength of Zhermack universal tray adhesive with addition silicone impression material was the highest and Coltene universal tray adhesive with condensation silicone impression material was the least of all the four groups.

Clinical significance: Tray adhesives need to be applied to the tray to obtain an accurate and consistent impression. If there is a separation of impression materials from the tray, it may results in a distorted impression leading to poor final restorations.

Keywords: Acrylic tray material, Adhesive bond strength, Elastomeric impression material, Separation failure, Universal tray adhesive.

The Journal of Contemporary Dental Practice (2019): 10.5005/jp-journals-10024-2699
\end{abstract}

\section{INTRODUCTION}

An impression should be dimensionally accurate for the fabrication of prosthesis because inaccurate impressions can compromise the function, fit, and esthetics of the restoration. When the impression is retrieved, it may be distorted if the impression material pulls away from the tray. ${ }^{1,2}$ The dimensional accuracy of elastomeric impression material is influenced by the adhesion of elastomeric impression materials to the impression tray. ${ }^{3,4}$

An impression material having a high tear resistance requires an adhesive that is effective, so that its removal from undercuts is at ease. ${ }^{5,6}$ The application of an adhesive is highly recommended irrespective of the tray being stock tray or custom tray, although some mechanical retention is provided by stock trays. ${ }^{7}$

\section{Materials and Methods}

Sixty flat square specimens $(20 \times 20 \times 20 \mathrm{~mm})$ were fabricated by autopolymerizing polymethyl methacrylate acrylic tray material. An eye hook was incorporated into each specimen to serve as the point of attachment to a screw-driven universal testing machine (Fig. 1). The specimen surface was polished with a 320-grit silicone carbide paper to standardize surface roughness. A piece of PVC pipe, $15 \mathrm{~mm}$ diameter and $25 \mathrm{~mm}$ long was used to house the impression
${ }^{1,5}$ Department of Prosthodontics, Srinivas Institute of Dental Sciences, Mangaluru, Karnataka, India

${ }^{2}$ Department of Prosthodontics, PSM College of Dental Science and Research, Thrissur, Kerala, India

${ }^{3}$ Department of Pedodontics and Oral Health, College of Dentistry, Al-Azhar University, Cairo, Egypt

${ }^{4}$ Department of Preventive Dental Sciences, College of Dentistry, Prince Sattam Bin Abdulaziz University, Al-Kharj, Kingdom of Saudi Arabia

${ }^{6}$ Department of Prosthodontics and Crown and Bridge, Kalinga Institute of Dental Sciences, Deemed to be University, Bhubaneswar, Odisha, India

Corresponding Author: Sapna C Kambiranda, Department of Prosthodontics, Srinivas Institute of Dental Sciences, Mangaluru, Karnataka, India, Phone: +91 9449767433, e-mail: sapna_chengappa@ yahoo.com

How to cite this article: Kambiranda SC, Pinto B, Elpatal MA, et al. Evaluation of the Bond Strength of Universal Tray Adhesives on Silicone Impression Materials Using an Acrylic Tray. J Contemp Dent Pract 2019;20(12):1406-1411.

Source of support: Nil

Conflict of interest: None

() The Author(s). 2019 Open Access This article is distributed under the terms of the Creative Commons Attribution 4.0 International License (https://creativecommons. org/licenses/by-nc/4.0/), which permits unrestricted use, distribution, and non-commercial reproduction in any medium, provided you give appropriate credit to the original author(s) and the source, provide a link to the Creative Commons license, and indicate if changes were made. The Creative Commons Public Domain Dedication waiver (http://creativecommons.org/publicdomain/zero/1.0/) applies to the data made available in this article, unless otherwise stated. 


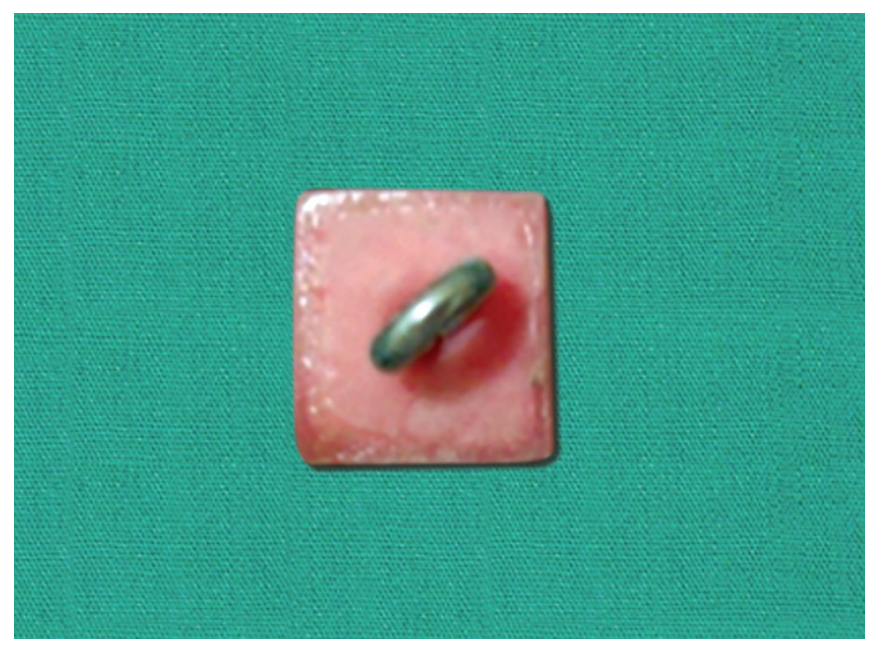

Fig. 1: Autopolymerizing acrylic tray material specimen with an attached eye hook

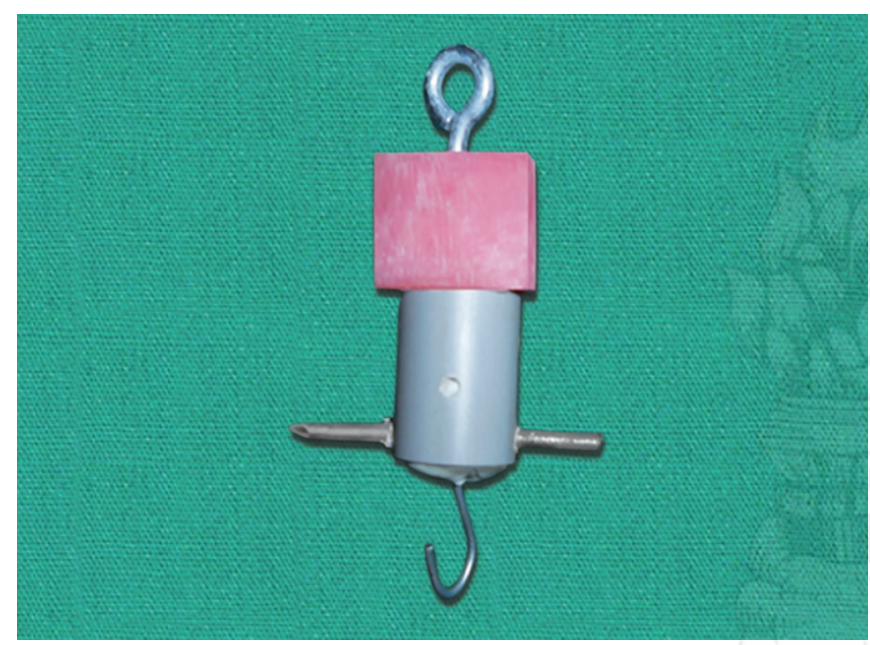

Fig. 3: Specimen to be secured to universal testing machine

material (Fig. 2). To increase material retention beyond that resulting from the use of adhesive, the cylinder was perforated in multiple locations, providing additional mechanical retention (Fig. 2). A metal rod was inserted into two centered holes to provide retention for the eyehook that served as the second point of attachment to the universal testing machine (Fig. 3).

\section{Specimen Selection}

The specimens were divided into 4 groups of 15 specimens each.

\section{Group I (Fig. 4A)}

- Group I of fifteen specimens was coated with Coltene universal tray adhesive. A thin coat was applied on the polished acrylic resin surface to be in contact with the PVC pipe.

- The solvent in the adhesive was allowed to dry for about 10 minutes.

- The perforated PVC pipe housing was then centrally placed in contact with the tray material.

- The addition silicone impression material was mixed and dispensed into the PVC pipe housing.

- The metal rod and hook were inserted at the open end of the cylinder and the impression material was allowed to polymerize.

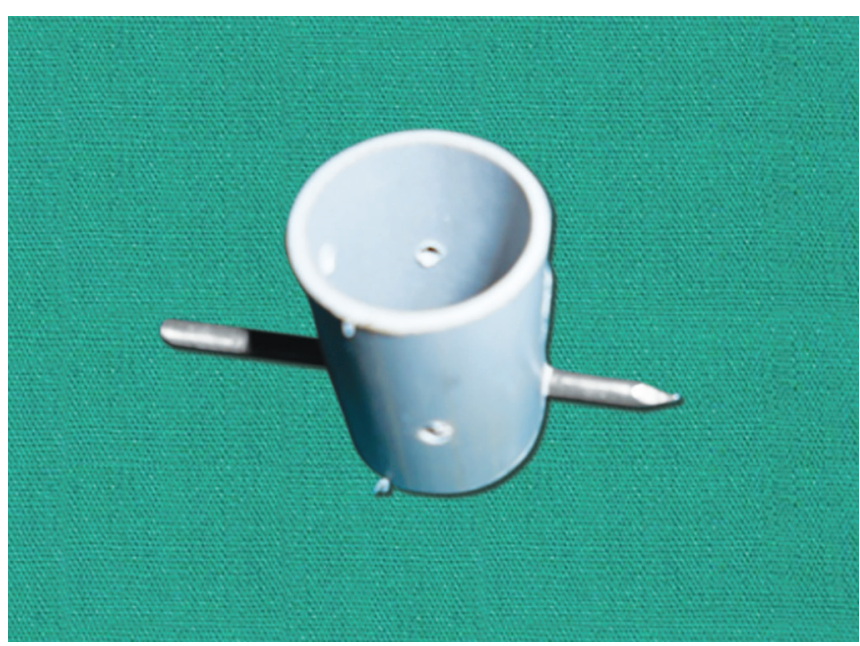

Fig. 2: Polyvinyl chloride pipe housing the elastomeric impression material with metal rod inserted

\section{Group II (Fig. 4B)}

- Group II of fifteen specimens was coated with Zhermack universal tray adhesive. A thin coat was applied on the polished acrylic resin surface to be in contact with the PVC pipe.

- The solvent in the adhesive was allowed to dry for about 10 minutes.

- The perforated PVC pipe housing was then centrally placed in contact with the tray material. The addition silicone impression material was mixed and dispensed into the PVC pipe housing.

- The metal rod and hook were inserted at the open end of the cylinder and the impression material was allowed to polymerize.

\section{Group III (Fig. 5A)}

- Group III of fifteen specimens was coated with Coltene universal tray adhesive; a thin coat was applied on the polished acrylic resin surface to be in contact with the PVC pipe.

- The solvent in the adhesive was allowed to dry for about 10 minutes.

- The perforated PVC pipe housing was then centrally placed in contact with the tray material.

- The condensation silicone impression material was mixed and dispensed into the PVC pipe housing.

- The metal rod and hook were inserted at the open end of the cylinder and the impression material was allowed to polymerize.

\section{Group IV (Fig. 5B)}

- Group IV of fifteen specimens was coated with Zhermack universal tray adhesive. A thin coat was applied on the polished acrylic resin surface to be in contact with the PVC pipe.

- The solvent in the adhesive was allowed to dry for about 10 minutes.

- The perforated PVC pipe housing was then centrally placed in contact with the tray material.

- The condensation silicone impression material was mixed and dispensed into the PVC pipe housing.

- The metal rod and hook were inserted at the open end of the cylinder and the impression material was allowed to polymerize. 

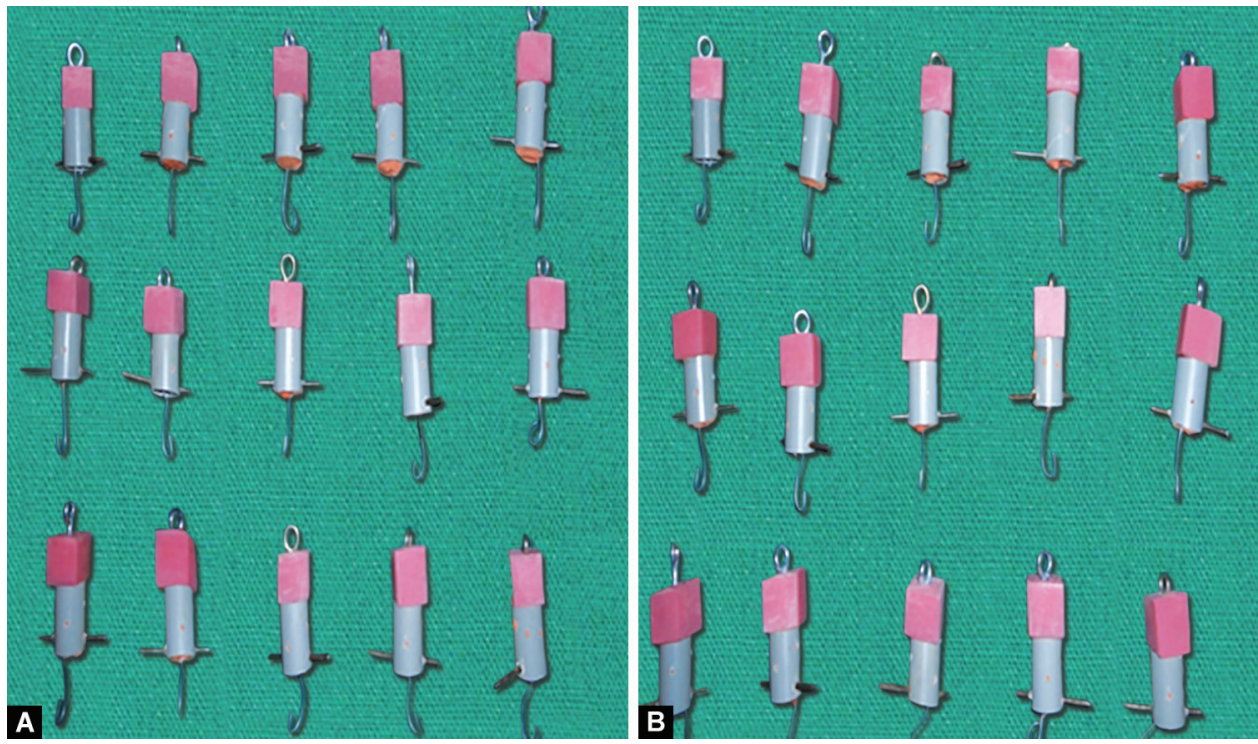

Figs 4A and B: (A) Group I-autopolymerizing acrylic tray material specimens coated with Coltene universal tray adhesive in contact with addition silicone impression material; (B) Group II-autopolymerizing acrylic tray material specimens coated with Zhermack universal tray adhesive in contact with addition silicone impression material
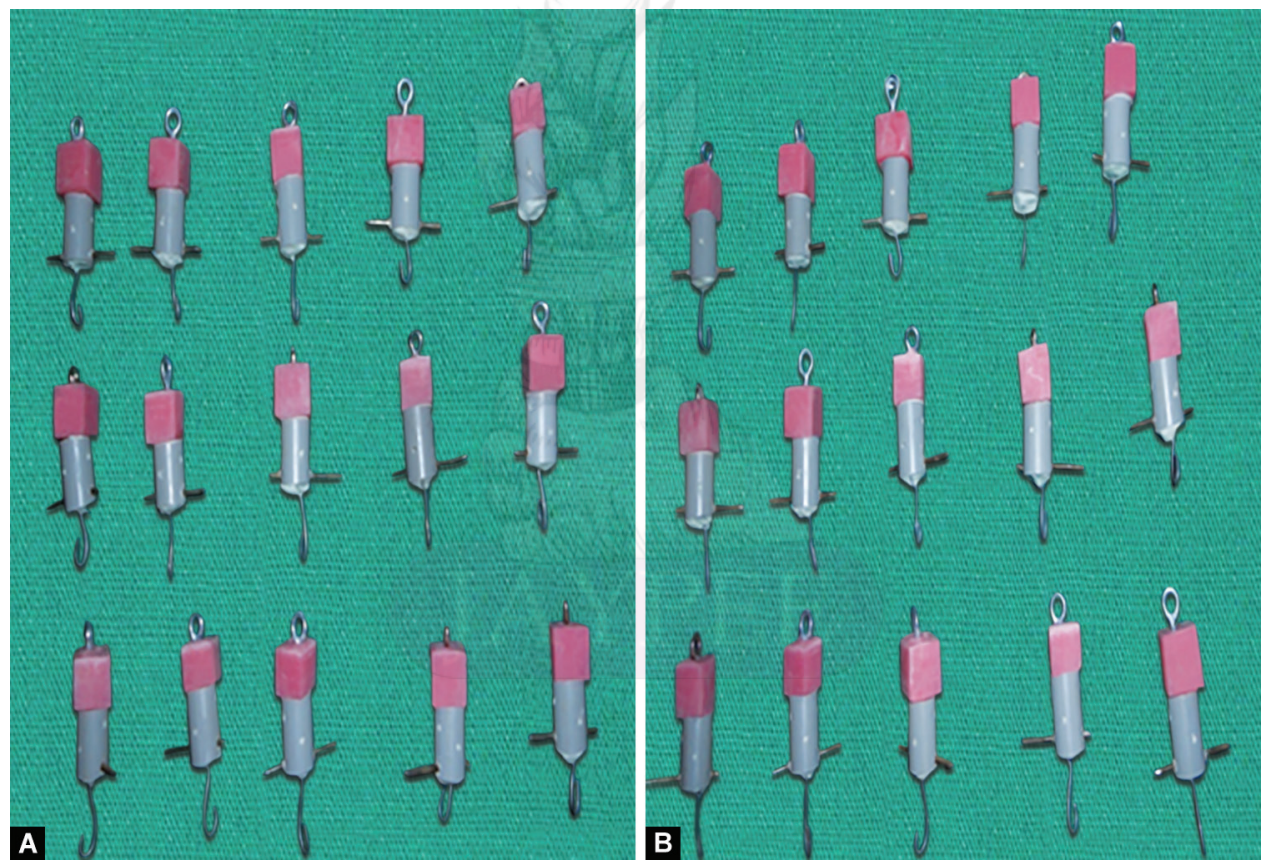

Figs 5A and B: (A) Group III-autopolymerizing acrylic tray material specimens coated with Coltene universal tray adhesive in contact with condensation silicone impression material; (B) Group IV-autopolymerizing acrylic tray material specimens coated with Zhermack universal tray adhesive in contact with condensation silicone impression material

Each specimen was then attached to the universal testing machine by means of metal hooks attached to the eye hooks in the tray specimen and the metal rod placed through the PVC pipe housing (Fig. 6). The specimens were then tested in tensile mode at a cross-head speed of $5 \mathrm{~mm} /$ minutes until separation failure occurred. The maximum force at which separation failure occurred was divided by the area of adhesion and recorded as the adhesive strength in MPa.

\section{RESULTS}

As can be seen from Table 1, the highest mean value of Zhermack universal tray adhesive with addition silicone impression material (0.35487) indicated the highest adhesive bond strength values followed by Zhermack with condensation silicone impression material (0.27440).

As shown in Table 2, Coltene universal tray adhesive (0.11750) showed a significantly lower mean value in comparison to Zhermack 
universal tray adhesive (0.31463). Coltene universal tray adhesive with addition silicone impression material (0.13987) had a higher mean value in comparison with Coltene universal tray adhesive with condensation silicone impression material (0.09513).

A significant difference was observed between mean MPa values of Zhermack and Coltene universal tray adhesives, where the $F$ value of 1314.116 was found to be significant at 0.000 levels. From the mean values it is clear that Zhermack adhesive (mean 0.31463) has higher MPa than Coltene adhesive (mean 0.1175).

Impression material comparison again indicated a significant difference $(F=132.514 ; p=0.000)$, where addition silicone (mean 0.247 ) had higher MPa than condensation silicone (mean 0.184).

Lastly, the interaction between adhesive and impression material was found to be significant $(F=10.794 ; p=0.002)$, where we found that with Zhermack universal tray adhesive, addition silicone

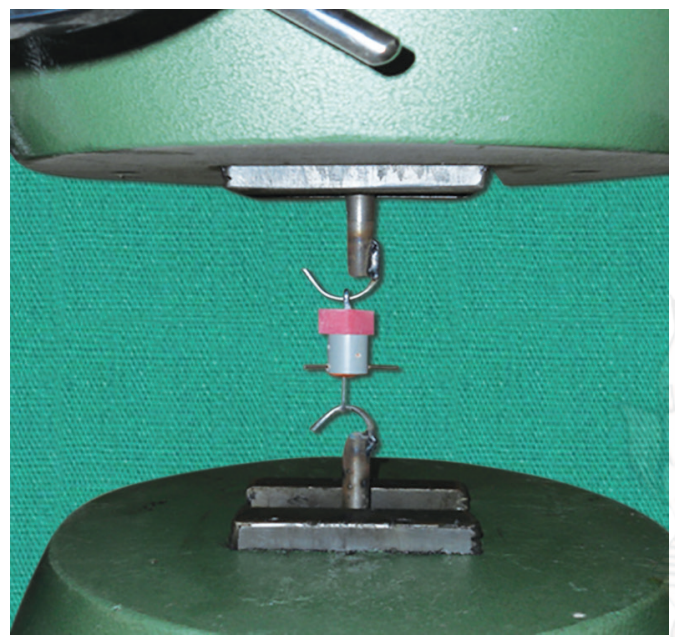

Fig. 6: Specimen tested using universal testing machine had higher MPa, whereas with Coltene universal tray adhesive, we do not find much variation between addition and condensation silicone impression material.

Independent-samples $t$ test revealed a significant difference in mean MPa values between:

- Groups I and II with a $t$ value of 20.253 and $p$ value of 0.001 . Group II had higher MPa (mean 0.354) than group I (mean 0.1398). The difference in mean MPa value was 0.215.

- Groups I and III with a $t$ value of 14.969 and $p$ value of 0.001 . From the Table 1 it is clear that group I had higher MPa (mean 0.13987 ) than group III (mean 0.09513). The difference in mean MPa value was 0.04473 .

- Groups I and IV with a $t$ value of -98.301 and $p$ value of 0.001 . From the Table 1 it is clear that group I had higher MPa (mean 0.13987 ) than group IV (mean 0.27440). The difference in mean MPa value was -0.13453 .

- Groups II and III with a $t$ value of 24.072 and $p$ value of 0.000 . From the Table 1 it is clear that group II had higher MPa (mean 0.35487) than group III (mean 0.09513). The difference in mean MPa value was 0.25973 .

- Groups II and IV with a $t$ value of 7.695 and $p$ value of 0.001 From the Table 1 it is clear that group II had higher MPa (mean 0.35487 ) than group IV (mean 0.27440). The difference in mean MPa value was 0.08047 .

- Groups III and IV with a $t$ value of -61.345 and $p$ value of 0.000 . From the Table 1 it is clear that group IV had higher MPa (mean 0.27440 ) than group III (mean 0.09513). The difference in mean MPa value was -0.17927 .

Figure 7 shows the adhesive bond strength values in MPa for all the four groups. The mean value (0.35) of group II indicated the highest bond strength value followed by group IV with a mean value of 0.27 , which was followed by group I with a mean value of 0.13 and lastly group III with a mean value of 0.09 .

Table 1: Mean MPa values of Zhermack and Coltene universal tray adhesives with addition and condensation silicone impression material

\begin{tabular}{llllrr}
\hline Adhesive & Impression material & Mean & Std. deviation & $n$ & CV \\
\hline Zhermack & Addition silicone & 0.35487 & 0.040364 & 15 & 11.37 \\
& Condensation silicone & 0.27440 & 0.003334 & 15 & 1.22 \\
& Total & 0.31463 & 0.049663 & 30 & 15.78 \\
Coltene & Addition silicone & 0.13987 & 0.004121 & 15 & 2.95 \\
& Condensation silicone & 0.09513 & 0.010816 & 15 & 11.37 \\
& Total & 0.11750 & 0.024129 & 30 & 20.54 \\
Total & Addition silicone & 0.24737 & 0.112914 & 30 & 45.65 \\
& Condensation silicone & 0.18477 & 0.091504 & 30 & 49.52 \\
& Total & 0.21607 & 0.106670 & 60 & 49.37 \\
\hline
\end{tabular}

Table 2: Results of two-way ANOVA for mean MPa values of Zhermack and Coltene universal tray adhesives with addition and condensation silicone impression materials

\begin{tabular}{llllrl}
\hline Source of variation & Sum of squares & Df & Mean square & \multicolumn{1}{c}{ Sig. } \\
\hline Adhesive & 0.583 & 1 & 0.583 & 1314.116 & $0.000(\mathrm{~S})$ \\
Material & 0.059 & 1 & 0.059 & 132.514 & $0.000(\mathrm{~S})$ \\
Adhesive $\times$ material & 0.005 & 1 & 0.005 & 10.794 & $0.002(\mathrm{~S})$ \\
Error & 0.025 & 56 & 0.000 & & \\
Total & 3.472 & 60 & & & \\
Corrected total & 0.671 & 59 & & & \\
\hline
\end{tabular}




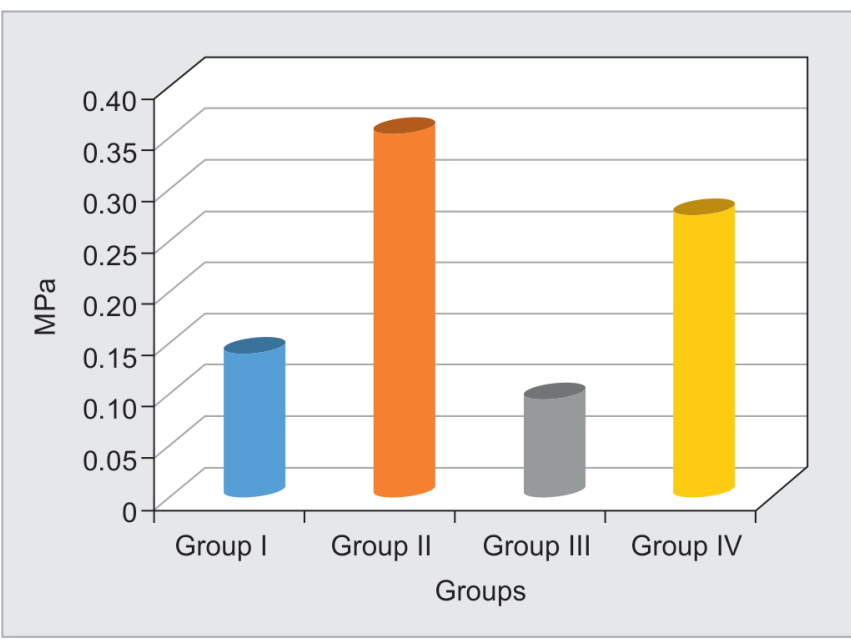

Fig. 7: Mean MPa values of Zhermack and Coltene universal tray adhesives with addition and condensation silicone impression materials

\section{Discussion}

Accuracy of the cast and the prosthesis is dependent on the retentiveness of the impression to the tray. If the impression material displaces from the tray, there is a possibility of the impression getting distorted on removal of the impression from the mouth. Application of the tray adhesive to the tray before making an impression greatly enhances the dimensional stability of elastomeric impression material. ${ }^{7}$

Peregrina et al. stated that using paint on universal tray adhesive provided higher adhesive bond strength values for the VPS impression materials when compared to the manufacturerrecommended adhesive to the autopolymerizing acrylic tray material tested. ${ }^{8}$

Philips stated that adhesives were more effective when used with polysulfides, polyethers, condensation silicones and less effective when compared with addition silicones. ${ }^{9,10}$ Tjan and Whang stated that a combination of adhesives and perforations gave the best overall adhesion. ${ }^{11}$ Previous studies that were conducted in various experimental conditions reported that when conventional universal adhesives are used, the bond strength of polyvinyl siloxane impression materials to acrylic tray materials in the range of $0.13-1.09 \mathrm{MPa} .^{12}$

However, studies that evaluated and compared the effectiveness of various universal tray adhesives on addition and condensation silicone are very limited. Therefore, this study attempts to evaluate and compare the effect of adhesive bond strength of two commercially available universal tray adhesives, Coltene and Zhermack, on addition and condensation silicone impression materials to an autopolymerizing acrylic tray material.

In the current study, the mean bond strength of $0.35 \mathrm{MPa}$ measured for addition silicone in combination with a Zhermack universal tray adhesive was within the range of data obtained from the previous studies. Both addition and condensation silicone impression materials when applied with Zhermack universal tray adhesive showed better adhesive bond strength when compared with Coltene universal tray adhesive.

The bond strength of the adhesive agent, custom tray material and the impression material used is directly related to

- The surface chemistry of the resin tray material that has been used

- The chemical properties of the adhesive agents. ${ }^{13}$
The significantly greater bond strengths of Zhermack universal tray adhesive were probably attributable to the higher adhesive capability of these adhesives. The adhesion of the tray adhesives is achieved because of chemical adhesion between the impression material and methyl methacrylate tray material.

On application, the carrier solvent present in the tray adhesive swells the outermost surface of the acrylic tray. This allows the interaction and penetration of adhesive with the impression material. In addition, there is evaporation of the solvent present in the adhesive which covers the entire tray surface, which is held within the molecular network of the impression material. ${ }^{14}$ Therefore, the use of an adhesive on the impression tray improves its adhesion to the impression material and directs the polymerization shrinkage toward the tray.

Polydimethylsiloxane and ethyl silicate are the contents of the tray adhesives used for silicone impression materials. Polydimethylsiloxane present in the adhesive adheres onto the impression material. A physical bond is formed with the methyl methacrylate impression material by the solvent-ethyl silicate forming hydrated silica. The ability of the solvent in the adhesive to dissolve the resin tray material determines the retention of impression materials to acrylic resin tray material. ${ }^{15}$ In order to provide time for the adhesive to react with the tray material, it is advisable to wait $10-15$ minutes before the impression is made.

Evaporation of the solvent in the adhesive is known as setting of the adhesive. It is dependent on temperature, humidity, and time. ${ }^{16}$

Therefore, in this present study, the better adhesive bond strength of Zhermack universal tray adhesive in comparison with that of Coltene universal tray adhesive may be attributed to the difference in the solubility of the tray material by the solvent present in the tray adhesive.

From the results obtained in the study, Zhermack universal tray adhesive with addition silicone impression material was recommended as an ideal tray adhesive-impression material combination using autopolymerizing polymethyl methacrylate acrylic resin as the tray material.

\section{Limitations of this Study Included}

- Further investigation to explain the reactivity of polydimethyl siloxane present in the tray adhesive with addition and condensation silicone impression material.

- As the study was conducted in vitro, further investigation needs to be carried out when applied clinically.

\section{Conclusion}

Within the limitation of this study,

- The adhesive bond strength of Zhermack universal tray adhesive was higher than that of Coltene universal tray adhesive regardless of the impression material used with the autopolymerizing acrylic resin as the tray material.

- Adhesive strength of Zhermack universal tray adhesive with addition silicone impression material was highest compared to all other groups.

- Adhesive strength of Coltene universal tray adhesive with condensation silicone impression material was the least compared to all other groups. 
In the present era of precision medicine, it is necessary to have detailed information of the bond strength and reaction of various tray adhesives with the tray and impression material, as it plays a crucial role in the accuracy of the cast and the prosthesis.

\section{References}

1. Cho GC, Donovan TE, Chee WW. Tensile bond strength of polyvinylsiloxane impressions bonded to a custom tray as a function of drying time: part 1. J Prosthet Dent 1995;73(5):419-423. DOI: 10.1016/S0022-3913(05)80068-X.

2. Poojya R, Jyothi PA. Influence of adhesives on the bond strength of vinylpolysiloxane to acrylic tray material. IJCD 2011;2(2):57-60.

3. Nishigawa G, Sato T, Suenaga K, et al. Efficacy of tray adhesives for the adhesion of elastomer rubber impression materials to impression modelling plastics for border moulding. J Prosthet Dent 1998;79(2):140-144. DOI: 10.1016/S0022-3913(98)70207-0.

4. Bomberg TJ, Goldfogel MH, Hoffman Jr W, et al. Considerations for adhesion of impression materials to impression trays. J Prosthet Dent 1988;60(6):681-684. DOI: 10.1016/0022-3913(88)90398-8.

5. Yi MH, Shim JS, Lee KW, et al. Drying time of tray adhesives for adequate tensile bond strength between polyvinylsiloxane impression and tray resin material. J Adv Prosthodont 2009;1(2):63-70. DOI: 10.4047/jap.2009.1.2.63.

6. Sulong MZ, Setchell DJ. Properties of the tray adhesive of an addition polymerizing silicone to impression tray materials. J Prosthet Dent 1991;66(6):743-747. DOI: 10.1016/0022-3913(91)90407-N.

7. Ciesco IN, Malone WFP, Sandrik JL, et al. Comparison of elastomeric impression materials used in fixed prosthodontics.
J Prosthet Dent 1981;45(1):89-94. DOI: 10.1016/0022-3913(81) 90018-4.

8. Peregrina AL, Wandling C, Johnston WM. The effect of different adhesives on vinyl polysiloxane bond strength to two tray materials. J Prosthet Dent 2005;94(3):209-213. DOI: 10.1016/ j.prosdent.2005.06.011.

9. Craig R, Powers J. Restorative dental materials, 11th ed., St. Louis: Mosby; 2001. p. 363.

10. Phillips RW, Skinner EW. Skinner's science of dental materials, 8th ed., Philadelphia: WB Saunders; 2008. p. 150.

11. Tjan AH, Whang SB. Comparing effects of tray treatment on the accuracy of dies. J Prosthet Dent 1987;58(2):175-178. DOI: 10.1016/0022-3913(87)90172-7.

12. Grant BE, Tjan AH. Tensile and peel bond strengths of tray adhesives. JProsthet Dent 1988;59(2):165-168. DOI: 10.1016/0022-3913(88)90009-1.

13. Payne JA, Pereira BP. Bond strength of two nonaqueous elastomeric impression materials bonded to two thermoplastic resin tray materials. J Prosthet Dent 1995;74(6):563-568. DOI: 10.1016/S00223913(05)80306-3.

14. Marafie $Y$, Looney S, Nelson S. Retention strength of impression materials to tray material using different adhesive methods. J Prosthet Dent 2008;100(6):432-444. DOI: 10.1016/S0022-3913(08)60260-7.

15. Ona $M$, Takahashi $H$, Sato $M$, et al. Effect of reactive adhesives on the tensile bond strength of polyvinyl siloxane impression materials to methylmethacrylate tray material. Dent Mater J 2010;29(3):336-340. DOI: 10.4012/dmj.2009-096.

16. Leung KC, Chow TW, Woo EC. Effect of adhesive drying time on the bond strength of irreversible hydrocolloid to stainless steel. J Prosthet Dent 1999;81(5):586-590. DOI: 10.1016/S0022-3913(99)70214-3. 